\title{
INICIATIVAS INTERNACIONAIS: UM ESTUDO COMPARATIVO SOBRE A CONSTRUÇÃO DA COMUNICAÇÃO ORGANIZACIONAL NO BRASIL E NA FRANÇA'
}

\author{
INTERNATIONAL INITIATIVES: A COMPARATIVE STUDY ON THE \\ CONSTRUCTION OF ORGANIZATIONAL COMMUNICATION \\ IN BRAZIL AND FRANCE \\ INICIATIVAS INTERNACIONALES: UN ESTUDIO COMPARATIVO SOBRE LA \\ CONSTRUCCIÓN DE LA COMUNICACIÓN ORGANIZACIONAL \\ EN BRASIL Y FRANCIA
}

\section{Alice Zozima Paris Rego de Souza ${ }^{2}$ Margarida Maria Krohling Kunsch ${ }^{3}$}

RESUMO: Por meio de uma pesquisa exploratória, de caráter teórico-reflexivo, sobre a evolução da institucionalização cognitiva e social de um campo de disciplina, este artigo procura mostrar os desafios da construção da comunicação organizacional entre dois países - a França e o Brasil. A comunicação internacional e a comunicação intercultural são utilizadas pelas práticas profissionais e acadêmicas por intermédio da influência política e econômica dos Estados Unidos. O texto esclarece as particularidades e os pontos de interação de cada tipo de comunicação, visando assim compreender as nuances, os pontos de conexão e as pistas de colaboração entre elas.

\footnotetext{
Este artigo apresenta um pequeno recorte de uma pesquisa mais ampla, desenvolvida em nível de doutorado por Alice Zozima Paris Rego de Souza, sob a orientação de Eric Boutin, na École Doctorale 509 en SHS - Civilisations et Sociétés Euro-Méditerranéennes et Comparées, da Université de Toulon, França, e coorientação de Margarida Maria Krohling Kunsch, em convênio de cotutela com o Programa de Pós-Graduação em Ciências da Comunicação da Escola de Comunicações e Artes da Universidade de São Paulo (ECA-USP), Brasil.

2 Université de Toulon, Toulon, França. ORCID: 0000-0001-9862-2905. E-mail: alice_zozima@hotmail.com 3 Universidade de São Paulo, São Paulo, SP, Brasil. ORCID: 0000-0002-7125-0053. E-mail: mkkunsch@usp.br
} 
Palavras-chave: Comunicação organizacional. Construção de disciplina. França e Brasil.

ABSTRACT : Through an exploratory, theoretical-reflexive research about the evolution of the cognitive and social institutionalization of a disciplinary field, this article focuses on the challenges in the construction of organizational communications in two countries - France and Brazil. The international coomumunicattion and the intercultural communication are used by professional and academic practices under the political and economic influence of the United States. The text sheds light on the peculiarities and the points of interaction with each communication aiming to understand the nuances, the points of connection and the ways of collaboration between them.

Keywords: Organizational communication. Building a discipline. France and Brazil.

RESUMEN: A través de una investigación exploratoria, de carácter teórico-reflexivo, sobre la evolución de la institucionalización cognitiva y social de un campo de disciplina, este artículo busca mostrar los desafíos de la construcción de la comunicación organizacional entre dos países - Francia y Brasil. La comunicación internacional y la comunicación intercultural son utilizadas por las prácticas profesionales y académicas a través de la influencia política y económica de los Estados Unidos de América. El texto aclara las particularidades y los puntos de interacción de cada tipo de comunicación, buscando así comprender los matices, los puntos de conexión y las pistas de colaboración entre ellas.

Palabras claves: Comunicación organizacional. Construcción de disciplina. Francia y Brasil.

\section{Introdução}

A comunicação internacional e a comunicação intercultural podem ser abordadas sob diferentes ângulos, tanto no contexto global da sociedade quanto em um quadro mais focado em ambientes específicos entre dois ou mais países. É possível explorá-las e estudá-las de maneiras diferentes, por exemplo, nos campos da ciência e da tecnologia, por meio de intercâmbios acadêmicos e científicos, em instituições e órgãos intergovernamentais, na cultura, nas artes e, principalmente, em interesses políticos e de outra natureza. na comunicação intercultural etc.

Este artigo objetiva analisar alguns aspectos interculturais existentes nas trocas internacionais com comunidades acadêmicas dentro da comunicação organizacional no Brasil e na França, concentrando-se em um grupo de pesquisa, publicações específicas e associações científicas no campo das Ciências da Informação e da Comunicação (CIC) entre esses dois países. Ele procura mostrar 
que é preciso primeiro conhecer e estar familiarizado com a institucionalização cognitiva e social ${ }^{4}$ da comunidade científica de cada um dos dois países, a fim de compreender suas diferenças e, em seguida, poder criar laços comuns. Em uma perspectiva genealógica de observação das referências primárias nas quais os pesquisadores se baseiam em seus textos, buscou-se primeiro entender a construção do campo acadêmico e disciplinar da comunicação organizacional e, em seguida, em quais pilares teóricos eles estavam apoiados. Embora em uma perspectiva panorâmica, analisou-se também a forma como o campo foi configurado no contexto atual do Brasil e da França em termos de iniciativas internacionais e interculturais.

Outro aspecto a considerar é que, segundo Pierre Bourdieu (1995), o campo científico constitui um espaço de pesquisa de reconhecimento público e político do conhecimento do produto. Busca-se a legitimação daqueles que se dedicam à construção de novas teorias, especialmente de sua visualização frente à comunidade acadêmica e à sociedade. Nesse contexto, como podemos integrar o papel da mídia diante de uma globalização ainda essencialmente econômica que induz novos modos de vida e novas formas comportamentais de sobrevivência?

$\mathrm{O}$ artigo mostra como as relações interculturais e internacionais entre profissionais e pesquisadores foram tratadas na década de 1950. Como estudo de caso, discute-se a construção da comunidade acadêmica da comunicação organizacional, fazendo uma comparação entre dois países diferentes, França e Brasil. $O$ desafio do estudo foi mostrar que, mesmo que a história da implementação dessa disciplina seja marcada por influências e manipulações políticas e econômicas, a institucionalização social e cognitiva deu-se com base em pesquisas sólidas dentro de perspectivas aplicadas a um aperfeiçoamento da comunicação nas organizações. Nesse contexto, concluiremos que, para o desenvolvimento de projetos futuros, as perspectivas devem ser desenvolvidas de comum acordo em todas as áreas da comunicação.

\section{O poder da comunicação dentro da sociedade globalizada}

É notável o poder que a comunicação exerce no mundo contemporâneo. Essa comunicação precisa ser considerada não meramente como instrumento de divulgação ou transmissão de informações, reduzida a uma visão linear, mas como processo social básico e como um fenômeno presente na sociedade. Deve

4 Cf. BOURE, $2007 a$. 
ser concebida como um poder transversal que perpassa todo o sistema social global, incluindo nesse âmbito as organizações.

São muitos os autores que trabalham a sociedade da informação, do conhecimento ou digital e que analisam a sociedade midiática, midiatizada, transparente e da comunicação. As tecnologias da informação e da comunicação estão definitivamente revolucionando a sociedade e seu modo de vida. Os exemplos são evidentes nas indústrias culturais, nas indústrias criativas, na multimídia, na televisão (interativa, digital, por cabo e de alta definição), nos aparelhos móveis e em todas as interações das mídias disponíveis em forma de redes digitais (blogs, Facebook, Twitter etc.). Toda essa convergência midiática é uma realidade presente nos dias de hoje e acontece no plano individual, na sociedade e em os todos os espaços - familiar, de trabalho e de participação social.

No livro Comunicación y poder, Manuel Castells (2009, p. 3) afirma:

Poder é algo mais que comunicação e comunicação é algo mais que
poder. Mas o poder depende do controle da comunicação. Igualmente
o contra-poder depende de romper o dito controle. E a comunicação
de massa, a comunicação que pode chegar a toda a sociedade, se
conforma e é gerida mediante relações de poder enraizadas no ne-
gócio dos meios de comunicação e da política do Estado. O poder da
comunicação está no centro da estrutura e da dinâmica da sociedade.

Castells (2009, p. 24-25) questiona "por que, como e quem constrói e exerce as relações de poder mediante a gestão dos processos de comunicação e de que forma os atores sociais que buscam a transformação social podem modificar essas relações influenciando na mente coletiva". Para ele, o "processo de comunicação opera de acordo com a estrutura, a cultura, a organização e a tecnologia de comunicação de uma determinada sociedade" (CASTELLS, 2009, p. 24).

Rafael Alberto Pérez (2008, p. 445) relaciona o poder da comunicação com o poder da comunicação estratégica e sintetiza da seguinte forma: "a comunicação tem um poder muito superior do que costumamos conceder a ela". Para o autor, "esse poder pode ser 'domado' se atuamos/comunicamos estrategicamente". Daí pode-se perceber o papel relevante exercido pelos atores envolvidos nas indústrias das comunicações e nas esferas do poder social, econômico e político, como veremos adiante, dentro da criação e do desenvolvimento de certas formações acadêmicas.

Segundo Christian Agbobli (2015), para que uma tradição de pesquisa se torne firmemente ancorada no mundo científico, deve adquirir reconhecimento 
científico, associando-os a programas universitários e associações científicas. No entanto, não podemos esquecer que vivemos em um tempo globalizado e em constante mudança. Para isso, ele explica que a comunicação internacional terá que se adaptar:

Com o advento da Internet, o fenômeno da globalização, o surgimento de movimentos sociais alternativos e o surgimento na esfera geopolítica dos países emergentes (como os Brics ou o N-11), a tradição da pesquisa em comunicação internacional é diversificada e é marcada por novas tendências e desafios. A comunicação internacional não se limita mais aos poderes tradicionais do Estado e à mídia tradicional, mas inclui novos atores estatais, novas organizações e novas questões (AGBOBLI, 2015, p. 67).

Da mesma forma, a comunicação desempenha um papel cada vez mais importante no contexto da globalização e das transformações gerais que caracterizam nossa realidade atual, forçando as pessoas a aprender a trabalhar em conjunto com diferentes culturas e a enfrentar novas realidades dentro de campos de atividades ainda mais diversos.

\footnotetext{
Para que seja possível promover a interação entre culturas nas mais variadas dimensões da sociedade, a prática de uma efetiva comunicação intercultural será imprescindível. Somente com essa comunicação que leve em conta o conhecimento, a língua e o respeito a outras culturas diferentes, diversidade, pluralidade, busca de entendimentos e de convívios amigáveis, por meio do diálogo, será possível a existência do verdadeiro interculturalismo (KUNSCH, 2017, p. 343).
}

Dentro dessa perspectiva de adaptação e de novas tendências procuramos encontrar um diferencial com estudos baseados nas raízes genealógicas da criação de uma disciplina e suas influências, já que, segundo Boure (2007b, p. 258), "conhecer e entender o passado possibilita pensar e agir no presente, especialmente quando se trata de assuntos ainda vivos". Veremos assim que a comunicação, antes de tudo, procura se desenvolver dentro do campo prático para em seguida conquistar um público maior, o acadêmico. 


\section{Uma história genealógica marcada pelo desenvolvimento industrial}

Nosso estudo buscou traçar, dentro duma perspectiva genealógica, o caminho percorrido pela comunidade científica e acadêmica da comunicação organizacional francesa e brasileira. Vimos através de um abrangente trabalho de pesquisa com fontes primárias que a comunicação organizacional na França e no Brasil teve em suas origens as bases norte-americanas. De fato, veremos que a comunicação internacional e intercultural está, em certa medida, diretamente relacionada à prática de como trabalhar iniciativas sustentáveis entre esses países.

Essas iniciativas sustentáveis serão marcadas por um longo processo de sedução de profissionais de relações internacionais. No Brasil, podemos citar as grandes vantagens oferecidas às empresas estrangeiras, principalmente as norte-americanas, em 1950, pelo presidente da República Juscelino Kubitschek de Oliveira. Graças ao trabalho das relações internacionais, as indústrias se instalarão em um momento único na história brasileira, participarão diretamente do desenvolvimento industrial e político do Brasil.

Um ponto a ressaltar nesta história é que o presidente Kubitschek era um homem de audácia: no mesmo período, ele decidiu construir a nova capital do País, Brasília, no meio do nada. Para isso, ele foi forçado a laminar o planalto central para abrir estradas de acesso aos quatro cantos do território nacional. Quatro pontos cardeais que saíram do centro de Brasília, chamados por ele de "cruzeiro de estradas -encruzilhada". Este trabalho durou cerca de cinco anos, o tempo de seu mandato, e marcou a história do Brasil para sempre. Entre 1955 e 1961, cerca de 13 mil quilômetros de estradas federais foram construídos. Ele conseguiu aumentar a taxa de investimento do Brasil em 10\% do PIB (FABER; ADORNE FILHO; AGUIAR, 2010).

Paralelamente a essa situação política do Brasil, o setor de comunicação entrará em uma nova fase, com a transmissão da televisão e o nascimento de vários jornais, rádios e revistas. Mas quem diz novas instalações, novas regras e novas leis, também diz problemas sindicais, greves e insatisfação em ambos os lados da moeda, tanto do lado dos empresários quanto do lado dos empregados. O papel dos relações-públicas, já conhecido pelos brasileiros desde o início do século XX (TORRES, 2002), será fundamental dentro dessa adaptação entre os patrões e os seus trabalhadores. É assim que as sociedades de relações públicas foram criadas no Brasil, como, por exemplo, a Companhia Nacional de Relações Públicas e Propaganda, em 1952. Nos anos seguintes, em 1954, surgiu 
a Associação Brasileira de Relações Públicas (ABRP), formada por um grupo de profissionais que queriam formalizar a profissão, e, em 1962, a Consultoria em Relações Públicas (AAB).

Desta forma, um novo período será estabelecido, pois os norte-americanos vão, de certa forma, criar uma dinâmica entre os profissionais de relações públicas brasileiros que queriam ser instrutores e atingir ainda mais chefes de empresas. Os formadores americanos do setor das relações públicas vão começar, a partir de 1953, a montar no Brasil novas equipes com o objetivo ensinar aos chefes de empresas como comunicar-se com os seus empregados. Treze anos mais tarde, mais de trezentas grandes empresas brasileiras contavam com serviços de relações públicas (CHAVES, 1966).

Em outubro de 1967, no anfiteatro central da empresa Pirelli, em São Paulo, durante a Convenção Nacional de Editores de Jornais e Revistas de Empresas, foi criada a Associação Brasileira de Editores de Revistas e Jornais de Empresas (Aberje), sob a direção de Nilo Luchetti, responsável pela revista interna Notícias Pirelli. Essa publicação teria o apoio total da direção e lidaria com assuntos sob a direção das relações humanas. O objetivo era estimular a inteligência, o enriquecimento interno, a cultura e a educação dos empregados dentro e fora da empresa. Essa foi considerada a primeira publicação interna a tratar o funcionário como "trabalhador leitor" (LUCHETTI, 1973).

A Aberje iria atuar como um fio condutor da comunicação dentro e fora das empresas. Ela foi lançada por profissionais treinados por um grupo de comunicadores de empresas, empregados em empresas multinacionais e brasileiras (Pirelli, Volkswagen, Alcan, Willys Overland, General Electric, entre outras), localizadas basicamente em São Paulo. Essa nova associação surgiu para quebrar o impasse de imagens das empresas, pois era necessário discutir e trocar ideias sobre a maneira como se comunicar nas organizações. Com ela teriam início os estudos de comunicação organizacional. Veremos que o Brasil e a França estavam mais próximos do que nunca nessa iniciativa.

A França também seria influenciada por profissionais de relações públicas norte-americanos, em um contexto um pouco diferente. Após a Segunda Guerra Mundial, entre 1945 e 1955, ela seria forçada a se reconstruir como país, para o que receberia ajuda americana por meio do chamado Plano Marshall, marcando-se este período pelo seu desenvolvimento econômico. No entanto, como no Brasil, as empresas estabelecerão novas regras indo contra as forças sindicais. A França seria marcada por tempos de greve e um longo período de insatisfação de ambos os lados. O Plano Marshall contribuiria para a criação, em 1950, de um 
Comitê Nacional de Produtividade (NPC), no qual representantes sindicais e chefes de empresas, mediante a Associação Francesa para a Produtividade (AFAP), receberiam fundos para organizar missões de produtividade nos Estados Unidos. O objetivo dessas missões era fazer novas descobertas sobre a profissão de relações públicas. As empresas francesas viram uma oportunidade única de enviar seus executivos, engenheiros e representantes sindicais aos Estados Unidos, em uma "missão de produtividade", para estudar e aprender mais sobre essa nova maneira de gerenciar as organizações, em uma perspectiva de humanização dentro das relações trabalhistas (TANGUY, 2001, p. 72).

Em consequência, outras empresas começaram a desenvolver trocas internacionais com a ajuda das relações internacionais franco-americanas no interior de suas próprias filiais:

\footnotetext{
As filiais francesas dos grupos petroleiros americano, foram entre eles os primeiros a introduzirem na França os métodos aprendidos pelos seus executivos enviados em estágios aos U.S.A. dentro de suas sociedades mães. Foi assim que nasceram, na França, os primeiros serviços de "public relations", entre outros dentro das sociedades Esso e Caltex (BOIRY, 2003, p. 34).
}

Foi nesse clima de transparência que, em 1949, um grupo de profissionais de agências de propaganda e empreendedores criou o Club de la Maison de Verre (Clube da Casa de Vidro), que receberia mais tarde o ajuda da Associação Profissional de Consultores e Diretores de Relações Públicas e Sociais (Aprorep), montada em 1952 e regida pela Lei de 1901. Em 1955, as duas entidades tornaram-se inseparáveis, fusionando-se em Paris, sob a Associação Francesa de Relações Públicas (AFREP). O interesse dos profissionais era trocar experiências e formalizar um conceito de relações públicas mais adaptado à sociedade francesa. Lucien Matrat seria responsável pelo departamento de relações públicas da Caltex, agora mais conhecido como Grupo Total. Ele mudaria a imagem da empresa, estabelecendo ligações entre a Caltex e a Universidade de Bordeaux, graças a uma bolsa de estudos.

Em 1959, Lucien Matrat, com a participação de colegas de diferentes países - Bélgica, França, Alemanha, Itália e Países-Baixos -, funda o Centro Europeu das Relações Públicas (CERP). Juntos, todos esses órgãos aprovam o Código Internacional de Ética para as Relações Públicas, mais conhecido como Código de Atenas, adotado pela Assembleia Geral do Centro Europeu de Relações Públicas no dia 11 de maio de 1965, em Atenas. Este Código permanece em vigor até 
hoje e é respeitado pela Associação Internacional de Relações Públicas e seus membros praticantes no mundo inteiro. Ele foi inspirado na Declaração Universal dos Direitos Humanos, mantendo como valores a honestidade, a abertura de espírito, a justiça, o respeito, a integridade e a comunicação franca. Foi traduzido em quase sessenta línguas e entregue oficialmente a muitos chefes de Estado, incluindo o Soberano Pontífice (PARIS, 2017, p. 38).

Da mesma forma que o Brasil, também a França se dedicaria à comunicação de empresa. Dimitri Weiss é o primeiro autor que se pode identificar. Em 1971 ele publicou dois livros: Comunicação e imprensa corporativa; e Comunicação nas empresas industriais: contribuição de um estudo da imprensa corporativa. Além disso, foi autor de um ensaio bibliográfico, Relations industrielles, publicado pela Editora Sirey em 1973. Weiss estudou o papel das revistas internas e seu envolvimento na política de comunicação e de gestão de negócios dentro das empresas. Esse tipo de imprensa já tinha visto seus dias na França desde 1887, com o Boletim Comercial nas redes de vendas (Félix Potin) e nas organizações de seguros em vários lugares (Assurances Le Populaire) (MALAVAL, 1992, p. 11). Com Catherine Malaval (1992) podemos seguir as primeiras tentativas de house organ das indústrias Renault (1918, 1927 e 1939) e, sobretudo, o desenvolvimento desses boletins de informação (existem na verdade várias publicações ao mesmo tempo, destinadas a diferentes públicos internos). Essas publicações eram uma inovação à medida que na época, ao menos até os anos 1970, as empresas francesas se pautaram durante muito tempo por uma máxima de São Francisco de Sales: "O barulho não faz bem, e o bem não faz barulho". ${ }^{5}$

Sob o impulso dos acadêmicos, dos chefes de empresas e dos sindicalistas, Charles Pierre Guillebeau criou e dirigiu, em 1957, o Centre d'Études Littéraires Supérieures Appliquées (CELSA), na Faculdade de Letras de Paris. Seria o primeiro centro de ensino a introduzir dentro das empresas estudantes de letras e ciências humanas, hoje conhecido como Institut des Hautes Etudes de l'Information et de la Communication (GUIET, 2016). O mais interessante é que Nilo Luchetti e Dimitri Weiss passariam a trocar ideias, começando assim uma relação internacional muito florescente. Como Luchetti desejava ir mais longe, começou a procurar respostas fora do Brasil sobre a conscientização nas empresas, para o que contatou o professor Weiss, então na Universidade de Sorbonne-Pantheon, em Paris, grande estudioso da comunicação e da imprensa corporativa como já mencionamos. Weiss imediatamente enviou a Luchetti seus trabalhos para esclarecer suas ideias e seus

5 Tradução livre do original: "Le bien ne fait pas de bruit, le bruit ne fait pas de bien". 
estudos. Comunicações e imprensa corporativa e Comunicação nas organizações industriais estavam entre os livros enviados (LUCHETTI, 1997).

De fato, pode-se dizer que para todas essas iniciativas de comunicação dentro e fora das empresas, seja entre países como o Brasil ou a França, ou entre continentes, a comunicação internacional e a comunicação intercultural estão fortemente relacionadas: seja o intercultural com respeito à copresença cultural entre indivíduos ou grupos, seja o internacional com sua responsabilidade de trabalhar para uma boa política entre as nações. Essa relação entre indivíduos, grupos, estados e partes interessadas foi trabalhada por Christian Agbobli e Gaby Hsab no livro Communication internationale et communication interculturelle: regards épistémologiques et espaces de pratique, publicado em 2011. Hsab explica que, apesar de um domínio ter sua própria problemática, seus temas e seus setores de base conceituais e de vocabulários, "seus pilares e o telhado que cobre as casas estão muito perto, se não idênticos, e fazem parte dos saberes epistemológicos e metodológicos que viram nascer e prosperar" (HSAB; STOICIU, 2011, p. 11).

\section{Uma comunidade científica em construção: a comunicação organizacional}

Como toda disciplina, as relações públicas, a comunicação de empresa e a comunicação organizacional, a comunicação internacional e a comunicação intercultural foram primeiramente práticas profissionais antes de serem formalizadas, teorizadas e ensinadas. No entanto, essa dinâmica estabelecida entre profissionais e educadores e vice-versa abriu portas para novos interesses dentro de uma economia política e pública. O tempo de institucionalização não foi longo. É a partir deste momento que as relações entre profissionais acadêmicos, de empresas e de organizações não governamentais se estreitaram cada vez mais. O objetivo agora era ampliar e criar fundamentos teóricos para que essa dinâmica funcionasse nesse contexto de formação de novos representantes. No entanto, como vimos anteriormente, o interesse do governo nas trocas internacionais estava presente em todas essas iniciativas, fossem elas financeiras ou intelectuais. Dessa forma, é mais fácil entender que, para institucionalizar cognitivamente ou socialmente uma disciplina, não é suficiente ter vontade de simplesmente formular os princípios; é preciso contextualizar, analisar e desenvolver um programa de investigação. Mostraremos aqui o caso da construção da comunidade acadêmica da comunicação organizacional, seus desafios e seus caminhos institucionais dentro de um contexto globalizado. 
Quando falamos de uma comunidade acadêmica, pensamos de certa forma em um grupo de professores e de diretores de escolas em um encontro que tem como objeto decisões a serem tomadas no ano letivo. Por outro lado, quando falamos da comunidade científica, pensamos, caricaturalmente, em um grupo de cientistas "malucos" que falam sobre temas e assuntos incompreensíveis para a maioria da população. No entanto, essas duas comunidades são uma só. Não há diferenças intelectuais entre elas, apenas contextos organizacionais formais. A primeira será apresentada e discutida no contexto da institucionalização social (trabalhará na criação de grupos de trabalho, posições e financiamentos), enquanto a segunda estará no contexto da institucionalização cognitiva (onde ela estará preocupada com questões de pesquisa, conceitos e teorias) (BOURE, 2007a).

Dentro dessa formalização sobre a institucionalização cognitiva e social, Alex Mucchielli (2003, p. 14) lembra que

as teorias científicas não são meramente "conjecturas" ou "suposições"
criadas pela mente humana para explicar os problemas colocados
pelas teorias anteriores. Uma teoria científica é, antes de tudo, uma
"especulação". Para ser validada, deve ser confrontada com observa-
ção e experiência. Os erros assinalados, se houver, permitirão então
revisar a teoria assim "falsificada" e progredir no seu desenvolvimento.

Uma vez que os fundamentos teóricos e práticos das relações públicas tenham sido utilizados e seus papéis tenham sido bem desenvolvidos e explorados, uma nova pista se abriu, a da necessidade de compreender as ações das comunicações científicas e práticas dentro das organizações, sem esquecer a base, "do homem social”, este que precisa de dignidade, de integração e de informação, pois segundo Matrat (apud BOIRY, 2003, p. 60), "o fabricante de opinião é este que conhece, compreende, julga, se exprime e comunica".

Nosso estudo traçou esse caminho. Primeiramente, a evolução dos estudos de comunicação organizacional no Brasil e na França seria uma consequência do que já havia sido implementado anteriormente pelos relações-públicas. Digamos que os estudos de comunicação organizacional, inicialmente chamados de comunicação corporativa ou de empresa, trarão pontos inovadores para essa disciplina.

À medida que as empresas aumentam seu volume de negócios, a necessidade de se expandir para outros horizontes ou mesmo para se expatriar está presente. Por meio da Universidade Purdue, Charles Redding, formou um pequeno batalhão de professores que desenvolveram, até mesmo contradizendo o mestre dentro de uma nova perspectiva, essa comunicação dita organizacional, inicialmente 
considerada como uma disciplina funcionalista. Graças a Redding, Phillip Tompkins, Linda Putnam e outros pesquisadores norte-americanos, esta disciplina passaria a ser metodologicamente estudada e conceitualizada em diferentes países, desenvolvendo assim múltiplas perspectivas, tornando-se um real campo de estudo. No Brasil, ela seria estudada inicialmente pela Universidade de São Paulo, a partir de 1985, por um grupo de pesquisadores já dedicados ao assunto, como, principalmente, de forma pioneira, Gaudêncio Torquato e Margarida Kunsch. Na França, ela chegaria cinco anos mais tarde, em 1990, formada por um pequeno grupo de pesquisadores da Société Française de Sciences de l'Information et de la Communication (SFSIC), tendo sido seus pioneiros Pierre Delcambre, Gino Gramaccia, Christian le Moënne e Nicole D’Almeida.

Nesta pesquisa pudemos detalhar alguns pontos inusitados entre os dois países, como a temporalidade de cada país em termos de abordagem de pesquisa: no Brasil as formações e as pesquisas começaram nos anos 1960, configurando-se a comunicação organizacional no ano 1985, enquanto na França a construção da disciplina começaria a ser trabalhada a partir dos anos 1990. Outro ponto curioso de nossa pesquisa foi observar que os pesquisadores brasileiros têm uma relação aberta com o mundo profissional, a ponto de aceitar ativamente o financiamento de empresas dentro das universidades em troca de resultados para melhorar seu funcionamento. Esses investimentos são ainda deduzidos dos impostos. Por outro lado, esse modo de agir é usado de maneira diferente pelos pesquisadores franceses que preferem manter distância. A terceira observação é que o Brasil tenta seguir um quadro cronológico, traçando seus trabalhos e suas pesquisas em bancos de dados de acesso aberto, mostrando assim suas perspectivas, ao contrário dos franceses, que ainda não o fizeram até hoje (2018). Segundo Christian Le Moënne (2010, p. 285), os pesquisadores franceses hesitaram desde o início em escrever sua própria história, porque há muitas questões teóricas e institucionais dentro da comunicação organizacional francesa, afirmando a autora que "a ciência está se fazendo". No entanto, é difícil para um jovem pesquisador traçar sua genealogia, um marco em nosso trabalho de pesquisa (PARIS, 2017, p. 37-38).

No entanto, um ponto comum identificado em ambos os países é que eles estão totalmente relacionados à mãe-ciência da informação e comunicação. Eles também formariam pequenos grupos de estudos sobre diversos temas, onde primeiramente buscarão inspiração nas fontes e metodologias norte-americanas para trabalhar, produzir, analisar e sugerir novas metodologias adaptadas às suas próprias culturas. Como na França, por exemplo, seriam estudados os 
paradigmas: lógicos sociais de fenômenos de comunicação e informação, comunicação sistêmica, comportamentos de comunicação; comunicação sociotécnica e atividade. No Brasil, as perspectivas seriam estudadas com base no relacional/ inter-relacional, na complexidade sistêmica, na crítica do humanismo e, mais recentemente, na comunicação digital e nas redes. Não entraremos nos detalhes de cada perspectiva, porque esse não é o objetivo deste artigo.

No entanto, vemos que a comunicação internacional e intercultural contribuirá fortemente para a área de comunicação organizacional, independentemente da dificuldade do caminho liderado pelas comunidades científicas e acadêmicas no contexto das trocas científicas.

Isto é confirmado pelo estudo realizado por Jacques Gaillard, sobre cooperação científica e técnica com os países do Sul, publicado em 1999, com o subtítulo Peut-on partager la science? O autor explica que

o apoio à pesquisa ou a cooperação científica para o desenvolvimento são entidades cujos limites são mal definidos e cobrem definições que são frequentemente divergentes ou diferentes. Assim, algumas atividades de apoio à pesquisa podem fazer parte de programas de desenvolvimento, ao ponto de muitas agências ou doadores considerarem inadequado distinguir entre as atividades de apoio as pesquisas e de apoio ao desenvolvimento. Essas diferenças de análise também estão na origem das construções institucionais distintas (GAILLARD, 1999, p. 15).

\section{A visão das comunicações dentro do sistema universitário mundializado}

Podemos citar o princípio da "visão sistêmica do mundo" de Alex Mucchielli, onde, segundo ele, o sistema de comunicação é um conjunto recorrente, regular e identificável de formas de troca existentes, em certa temporalidade, entre os atores. Para ele, toda comunicação existe apenas em um sistema de comunicação:

Nenhum fenômeno existe isoladamente, sendo que sua própria existência é concretizada por uma inserção em um conjunto de outros fenômenos que formam um sistema com ele. São as relações mantidas com os demais elementos do sistema que lhe dão o essencial de suas características existenciais (MUCCHIELLI, 2003, p. 20). 
Para entender melhor essa visão de mundo, de mundialização e de globalização, Armand Mattelart explica que tudo isso é, sobretudo, um trabalho de integração de economias e sistemas de comunicação. Esses trabalhos levam à criação de novas disparidades entre países ou regiões e entre grupos sociais.

\begin{abstract}
A globalização é uma daquelas palavras-armadilhas que faz parte das noções instrumentais de que, sob a influência da lógica de mercado e sem o conhecimento dos cidadãos, se naturalizaram a ponto de se tornarem indispensáveis para estabelecer a comunicação entre pessoas de culturas muito diferentes. Esta linguagem funcional é um prêt-à-porter (pronto a vestir) ideológico que esconde as desordens da nova ordem mundial (MATTELART, 2008, p. 103).
\end{abstract}

Se voltarmos à nossa genealogia, saberemos que a comunicação organizacional, internacional e intercultural são disciplinas provenientes de outras correntes. A comunicação organizacional seguirá as impressões de seis diferentes escolas de pensamento descritas por Dimitri Weiss (1971): sociologia, antropologia, gestão, economia, psicologia e ciência política. No entanto, a comunicação internacional e a comunicação intercultural emergiriam de um conjunto de questões historicamente ancoradas em torno de noções do universalismo, internacionalização, mundialização, globalização, geolocalização ou diversidade cultural, assim como imigração, integração, identidade etc., conforme descrito por Agbobli e Rico (AGBOBLI; SOTELO, 2004; AGBOBLI, 2015).

Podemos citar aqui o trabalho realizado durante a Conferência Geral da Organização das Nações Unidas para a Educação, a Ciência e a Cultura (Unesco), em sua 33. ${ }^{a}$ reunião, realizada em Paris de 3 a 21 de outubro de 2005 . No documento da convenção sobre a proteção e promoção da diversidade das expressões culturais, defendeu-se a diversidade cultural como uma característica essencial da humanidade e como patrimônio comum de valorização e cultivo para o benefício de todos. "Diversidade cultural", segundo a Unesco, nesse documento,

refere-se à multiplicidade de formas em que as culturas de grupos e sociedades encontram sua expressão. Tais expressões são transmitidas entre e dentro de grupos e sociedades. A diversidade cultural manifesta-se não apenas nas diversas formas em que ela se expressa, se enriquece e se transmite no contexto do patrimônio cultural da humanidade, mas através da diversidade de suas expressões culturais, bem como diferentes formas de criar, produzir, divulgar, distribuir e 
desfrutar das expressões culturais, independentemente dos meios e tecnologias empregados (UNESCO, [2005]).

Acredita-se que essas contribuições da Unesco constituem pilares fundamentais para pensar e praticar a cidadania cultural, onde o respeito à diversidade é uma prerrogativa essencial.

Nesse contexto, para caracterizar como as universidades, no sentido mais amplo, organizam suas políticas, é possível observar suas práticas de cooperação, de desenvolvimento de programas e de valorização econômica (GAILLARD, 1999). Fizemos um estudo bibliográfico, onde nos concentramos em uma visão geral dos professores e pesquisadores franceses e brasileiros titulares e que vinham do grupo de pesquisa da comunicação organizacional. Revisamos as publicações de artigos e periódicos dessa disciplina entre 2007 e 2015. Para nossa grande surpresa, embora os autores estivessem lidando com o mesmo assunto, as fontes ou citações entre os dois países eram quase inexistentes. Outras observações foram feitas ${ }^{6}$.

No entanto, nos anos seguintes, essa situação vai mudar a partir do momento em que professores dos dois países vão trabalhar em harmonia com as iniciativas internacionais e interculturais baseadas dentro de perspectivas de intercâmbio. Podemos aqui notar que o Brasil foi o pioneiro nessas trocas, convidando pesquisadores franceses a participar como oradores em conferências organizadas pela Associação Brasileira de Pesquisadores de Comunicação Organizacional e de Relações Públicas (Abrapcorp). Como, por exemplo, a professora Arlete Bouzon, da Universidade de Toulouse, em 2008, que publicou "A incerteza da comunicação de risco diante das inovações na indústria" (BOUZON, 2009, p. 107-123). E Nicole D'Almeida, do Celsa da Universidade de Paris IV, que escreveu "Opinião pública, comunicação e regulação do mercado" (D'ALMEIDA, 2010, p. 135-153). Ambas também publicaram artigos na revista Organicom. Outras iniciativas mais teriam lugar, como, por exemplo, a organização do $3 .^{\circ}$ Seminário Internacional de Comunicação (SICO), realizado na Universidade Federal de Minas Gerais em 2014.

Em seguida, como em um acordo diplomático, a França fará o mesmo, convidando pesquisadores brasileiros a publicar em revistas francesas, como a Revue Communication \& Organization e a Revue Française des Sciences de l'Information et de la Communication, bem como a participar de eventos científicos internacionais, como já mencionados acima. Essas ações conjuntas de ambas as partes estão forjando uma comunidade que hoje tem uma forte relação com a criação

6 Cf. PARIS, 2017. 
de futuros acordos bilaterais e agrupamentos científicos. Existem atualmente (2018) iniciativas no processo de parcerias acadêmicas entre pesquisadores de diferentes universidades dos dois países, através de intercâmbios acadêmicos e diretrizes para a pós-graduação em cotutela.

\section{Considerações finais}

Neste caso, podemos concluir que, uma vez que compreendemos e configuramos as diferenças entre o funcionamento da institucionalização acadêmica, seja ela cognitiva ou social, em cada país, como, por exemplo, dentro da comunicação organizacional, o "fazer ciência" neste mundo globalizado é possível. No entanto, é preciso levar em conta que os interesses políticos e diplomáticos também estão presentes. Esta "art d'influencer" (MUCCHIELLI, 2010) desempenhará um papel muito importante nos intercâmbios internacionais, interculturais e organizacionais. Nada é feito ou deixado ao acaso, porque as comunicações internacionais, interculturais e organizacionais têm agentes que integram a sociedade civil aos movimentos sociais, gerados pelos fenômenos da globalização e da revolução tecnológica da informação e da comunicação. Os direitos humanos e da cidadania que transcendem as fronteiras nacionais, ONGs, associações, comunidades, ativistas e grupos de interesse sofrem pressão em torno da manipulação de objetivos comuns. Segundo Mucchielli (2010, p. 44),

\footnotetext{
a manipulação é inicialmente uma questão de manipulação de normas, de relações, de identidades, de espaços temporais. Deve ser visto que esses elementos não são puras representações. Eles não existem apenas no mundo das ideias. [...]. Uma relação não é só "pensamento", ela não pode não existir quando os atores estão presentes.
}

A reconstrução do país do após-guerra, na França, e a construção de uma nova capital, Brasília, no Brasil, forjaram duravelmente uma maneira de fazer uma comunicação transcendente em todos os níveis. Economicamente, com a instalação e realocação de empresas americanas com vantagens fiscais no Brasil e na França e intelectualmente, com trocas entre formadores, que serviram tanto a formar profissionais quanto treinar profissionais para virarem formadores. As questões políticas nesse contexto, nesta era da globalização, dentro dessas dinâmicas de instalação de comunidades acadêmicas, permitiram mostrar essas passarelas entre as iniciativas internacionais, interculturais e organizacionais. Como vimos, o passado forma perspectivas comunicativas para o presente e o futuro. 
Somada ao desenvolvimento tecnológico, essa visão de mundo, a globalização da economia e o cruzamento de fronteiras, com uma consequente migração generalizada da população, nos faz progredir em um sistema além do multiculturalismo. Nesse caso, é necessário aprender a trabalhar juntos com diferentes culturas e a enfrentar novas realidades nos mais diversos campos de atividade. Tais eventos alimentaram reações e novas formas de luta da sociedade civil organizada nos níveis local, nacional, regional e global (KUNSCH, 2017).

\section{Referências}

AGBOBLI, Christian. La communication internationale: état des lieux et perspectives de recherche pour le XXle siècle. Communiquer - Revue de Communication Sociale et Publique, n. 15, p. 65-84, 2015. https://doi.org/10.4000/communiquer.1678

AGBOBLI, Christian; SOTELO, Carmen Rico de. La communication internationale, le développement et l'interculturalité: la pratique du stage, son imaginaire et son enjeu thèorique. In: SAINT-CHARLES Johanne; MONGEAU, Pierre (org.). Communication: horizons de pratiques et de recherche. Québec: Presse de l'Université du Québec, 2005. p. 185-214. Disponível em: https://books.google.fr/books?hl=fr\&id=oyb5C1i2C-

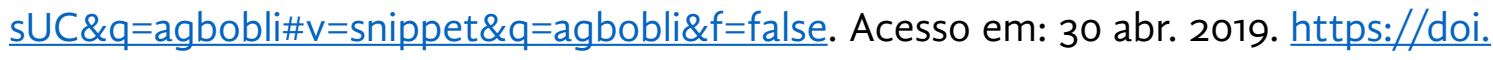
org/10.4000/rfsic. 955

BOIRY, Philippe A. Des public-relations aux relations publiques: la doctrine européenne de Lucien Matrat. Paris: L'Harmattan, 2003. https://doi.org/10.15448/19803729.2006.31.3404

BOURDIEU, Pierre. La cause de la science. Actes de la recherche en sciences sociales, V. 106-107, p. 3-10, 1995. https://doi.org/10.3406/arss.1995.3131

BOURE, Robert. Les sciences humaines et sociales en France: une approche historique. Cortil-Wodon: Editions Modulaires Européennes, 2007 a.

BOURE, Robert. L'histoire des sciences de l'information et de la communication. 2007b. Disponível em: http://questionsdecommunication.revues.org/7358. Acesso em: 30 abr. 2019.

BOUZON, Arlette. 2009. A incerteza da comunicação de risco diante das inovações na indústria. In: KUNSCH, Margarida M. Krohling; OLIVEIRA, Ivone de Lourdes (org.). A comunicação na gestão da sustentabilidade das organizações. São Caetano do Sul: Difusão, 2009. p. 107-123. https://doi.org/10.18225/9788570131485.capo3

CASTELLS, Manuel. Comunicación y poder. Madrid: Alianza Editorial, 2009. 
CHAVES, Sylla. Aspectos de relações públicas. DASP - Serviço de Documentação Departamento de Imprensa Nacional, 1966.

D’ALMEIDA, Nicole. Opinião pública, comunicação e regulação do mercado. In: KUNSCH, Margarida M. Krohling (org.). Comunicação pública, sociedade e cidadania. São Caetano do Sul: Difusão, 2010. p. 135-153. https://doi.org/10.15603/2175-7755/cs.v28n46p43-56

FABER, Marcos E. Ekman; ADORNE FILHO, Antenor; AGUIAR, Maria Francelina. O desenvolvimento econômico brasileiro e a industrialização no período Juscelino Kubitschek. Disponível em: http://www.historialivre.com/ brasil/jk1.htm. Acesso em: 30 abr. 2019.

GAILLARD, Jacques. La coopération scientifique et technique avec les pays du Sud: peut-on partager la science? Collection Hommes et sociétés. Paris: Karthala, 1999.

GUIET, Karine Berthelot. Celsa - Paris Sorbonne. 2016. Disponível em: http://www. celsa.fr/celsa.php. Acesso em: 30 abr. 2019.

HSAB, Gaby; STOICIU, Gina. Communication internationale et communciaiton interculturelle: des champs croisés, des frontières ambulantes. In: Communication internationale et communication interculturelle: regards épistémologiques et espaces de pratique. Québec: Presses de l'Université du Québec, 2011. p. 9-25. Disponível em: https://books.google.fr/books?id= jrEDhAgxugC\&printsec=frontcover\&hl=fr\&sour-

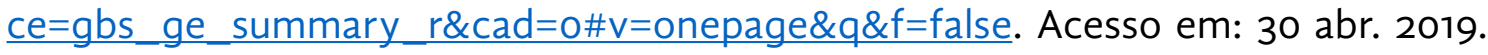
https://doi.org/10.7202/1024048ar

KUNSCH, Margarida M. Krohling. Comunicação intercultural e cidadania em tempos de globalização. In: MARTINS, Moisés de Lemos (org.). A internacionalização das comunidades lusófonas e ibero-americanas de ciências sociais e humanas: o caso das ciências da comunicação. Vila Nova de Famalicão (Portugal): Húmus, 2017. p. 337-354. Disponível em: http://www3.eca.usp.br/sites/default/files/form/biblioteca/ acervo/producao-academica/002864684.pdf. Acesso em: 30 abr. 2019. https://doi. org/10.11606/t.27.2006.tde-14052009-133509

LUCHETTI, Nilo. Parto normal - O artigo. Revista Comunicação Empresarial Aberje. São Paulo, a. 7, 1997. Disponível em: http://www.aberje.com.br/antigo/revista/n25/ artigo7d.htm. Acesso em: 30 abr. 2019.

LUCHETTI, Nilo. Parto natural. Revista Comunicação Empresarial Aberje. São Paulo, n. $25,1973$.

MALAVAL, Catherine. Renault à la une: la presse d'entreprise Renault depuis 1945 . Paris: ClioMédia, 1992.

MATRAT, Lucien; CLARIN, Alec. Les publics-relations: moteur de productivité. Paris: Elzevir, 1951. 
MATTELART, Armand. La mondialisation de la communication. Paris: Presses Universitaires de France, 2008. https://doi.org/10.7202/703825ar

MUCCHIELLI, Alex. L'art d'influencer: analyse des techniques de manipulation. Paris: Armand Colin, 2010.

MUCCHIELLI, Alex. Théorie systématique des communications: principes et applications. Paris: Armand Colin, 2003.

PÉREZ, Rafael Alberto. Estrategias de comunicación. Ariel: Google-Books-ID: Ki5AXzNODg8C, 2008.

PARIS, Alice Zozima Rego de Souza. O mundo das comunicações organizacionais: práticas e pesquisas. Um estudo genealógico, Brasil e França / Le monde des communications organisationelles: pratiques et recherches. Une étude généalogique, France et Brésil. 2017. Tese (Doutorado em Comunicação Organizacional) - École Doctorale 509 en SHS - Université de Toulon e em Cotutela com a Escola de Comunicação e Artes da Universidade de São Paulo, São Paulo, 2017. https://doi.org/10.11606/t.42.2019.tde12042018-141555

TANGUY, Lucie. Les promoteurs de la formation en entreprise (1945-1971). Travail et Emploi, n. 86, p. 27-47, abr. 2001.

TORRES, Mirtes. Eduardo Pinheiro Lobo. Pioneiro das relações públicas no Brasil. Salvador, 2002. Disponível em: http://www.portalrp.com.br/bibliotecavirtual/memoria/0174.pdf. Acesso em: 30 abr. 2019.

UNESCO - Organização das Nações Unidas para a Educação, a Ciência e a Cultura. Convenção sobre a proteção e promoção da diversidade das expressões culturais. Paris, 2005. Disponível em: www.cultura.gov.br/.../convencao...promocao-da-diversidade-das-expressoes-culturais. Acesso em: 30 abr. 2019. https://doi.org/10.23899/ relacult.v3i3. 573

Weiss, Dimitri. Communication et presse d'entreprise. Paris: Sirey,1971. https://doi. org/10.7202/028319ar

\section{Dados dos autores}

Alice Zozima Paris Rego de Souza - alice_zozima@hotmail.com

Doutorado em Sciences de l'Information et de la Communication pela Université de Toulon/ França, sob a orientação de Eric Boutin, em cotutela com a Escola de Comunicação e Artes da Universidade de São Paulo, sob a co-orientação de Margarida Maria Krohling Kunsch. Mestrado em Pesquisa em Sciences de I'Infor- 
mation et de la Communication no laboratório I3M (Information, Milieux, Médias et Médiations) e mestrado em Communication et Multimedias E-Redactionnel, ambos na Université de Toulon (França). Graduação em Lettres, Culture \& Nouveaux Médias pela Université de la Rochelle (França) e em Jornalismo pela Universidade Católica de Pernambuco.

Endereço: Université de Toulon, Université de Toulon - Campus de Toulon, 70 Avenue Roger Devoucoux Centre Ville, Toulon - França

\section{Margarida Maria Krohling Kunsch - mkkunsch@usp.br}

Professora titular da Universidade de São Paulo (USP). Ex-diretora (2013-2017) da Escola de Comunicações e Artes (ECA-USP), é pró-reitora adjunta de Cultura e Extensão Universitária da USP (gestão 2018-2021). Livre-docente em Teorias e Processos de Comunicação Institucional, doutora e mestre em Ciências da Comunicação pela ECA-USP. Coordenadora do Curso de Pós-Graduação Lato Sensu de Gestão Estratégica em Comunicação Organizacional e Relações Públicas da ECA-USP. Autora dos livros Planejamento de relações públicas na comunicação integrada, Relações públicas e modernidade: novos paradigmas na comunicação organizacional e Universidade e comunicação na edificação da sociedade. Organizadora de quase 40 coletâneas de Ciências da Comunicação, Comunicação Organizacional e Relações Públicas.

Endereço: Universidade de São Paulo, Escola de Comunicações e Artes, Av. Prof. Lucio Martins Rodrigues, 433, Cidade Universitária, São Paulo (SP) - Brasil 